\title{
Urquhart's and Garfield's Laws: The British Controversy Over Their Validity
}

\author{
Stephen J. Bensman \\ LSU Libraries, Louisiana State University, Baton Rouge, LA 70803. E-mail: notsjb@/su.edu
}

The British controversy over the validity of Urquhart's and Garfield's Laws during the 1970s constitutes an important episode in the formulation of the probability structure of human knowledge. This controversy took place within the historical context of the convergence of two scientific revolutions - the bibliometric and the biometric - that had been launched in Britain. The preceding decades had witnessed major breakthroughs in understanding the probability distributions underlying the use of human knowledge. Two of the most important of these breakthroughs were the laws posited by Donald $\mathrm{J}$. Urquhart and Eugene Garfield, who played major roles in establishing the institutional bases of the bibliometric revolution. For his part, Urquhart began his realization of S. C. Bradford's concept of a national science library by analyzing the borrowing of journals on interlibrary loan from the Science Museum Library in 1956. He found that $10 \%$ of the journals accounted for $80 \%$ of the loans and formulated Urquhart's Law, by which the interlibrary use of a journal is a measure of its total use. This law underlay the operations of the National Lending Library for Science and Technology (NLLST), which Urquhart founded. The NLLST became the British Library Lending Division (BLLD) and ultimately the British Library Document Supply Centre (BLDSC). In contrast, Garfield did a study of 1969 journal citations as part of the process of creating the Science Citation Index (SCI), formulating his Law of Concentration, by which the bulk of the information needs in science can be satisfied by a relatively small, multidisciplinary core of journals. This law became the operational principle of the Institute for Scientific Information created by Garfield. A study at the BLLD under Urquhart's successor, Maurice B. Line, found low correlations of NLLST use with $\mathrm{SCl}$ citations, and publication of this study started a major controversy, during which both laws were called into question. The study was based on the faulty use of the Spearman rankcorrelation coefficient, and the controversy over it was instrumental in causing B. C. Brookes to investigate bibliometric laws as probabilistic phenomena and begin to link the bibliometric with the biometric revolution. This paper concludes with a resolution of the controversy by means of a statistical technique that incorporates Brookes' criticism of the Spearman rank-correla-

(C) 2001 John Wiley \& Sons, Inc. tion method and demonstrates the mutual supportiveness of the two laws.

\section{Historical Background of the Controversy}

During the mid-1970s, a major controversy erupted in Britain over the validity of the bibliometric laws posited by Donald J. Urquhart and Eugene Garfield. This controversy constitutes an important episode in the formulation of the probability structure of human knowledge. However, to understand the significance of this controversy, it is necessary to have some understanding of the historical context, within which it took place. This context was defined by two scientific revolutions, which were launched in Britain and are now starting to converge. One was the bibliometric revolution, which was driven by Britain's need to develop an efficient scientific information system as a result of economic and military pressures during the twentieth century. Its main locus was the Science Museum Library (SML) in the South Kensington area of London. The primary aim of the bibliometric revolution was to improve access to scientific literature through better abstracting and indexing services together with the establishment of a national science library. In achieving this aim, it laid the foundations of information science. The other revolution was the biometric one, which arose from an attempt in the latter part of the nineteenth century to place Darwin's theory of evolution on firm mathematical bases. Due to its origins, this revolution was focused on biology, and its main locus was University College London (UCL) in the Bloomsbury area of this city. The chief result of this revolution was the creation of modern inferential statistics. In the early stage, the most important figures of the biometric revolution were Francis Galton, Karl Pearson, W. F. R. Weldon, George Yule, and William Gosset or "Student"; in the latter stage, the important persons were Ronald A. Fisher, Pearson's son, Egon, Jerzy Neyman, and Maurice Kendall.

Bensman (2000) presented the thesis that the skewed distributions dominating library and information science are also inherent in many other biological and social phenom- 
ena. This provides the basis for the close connection between the bibliometric and biometric revolutions. For example, the first bibliometric law was developed by Lotka (1926), who can be considered part of the biometric revolution, as he was best known for his work in demography, mathematical biology, and evolutionary processes.

The bibliometric revolution proper began with the work of S. C. Bradford at the Science Museum Library (SML) in the era between World Wars I and II. In an effort to improve the scientific information system, Bradford (1934) with his staff developed the famous Law of Scattering as part of a plan to insure total coverage of scientific literature by the indexing and abstracting periodicals. As a function of this law, Bradford perceived the need for a national science library and turned the SML into Britain's central back-up library for scientific documents, developing the concept of document delivery.

However, the bibliometric revolution received its main impetus in the scientific information crisis that enveloped Britain after World War II. This crisis had its deeper roots in the rapid advance of science and the explosive growth of scientific literature, and it particularly affected special libraries, whose postwar plight has been described by Ashworth (1975) thus:

... [Special] libraries had developed rapidly because of the vital necessity for rapid finding of information during an unprecedently technological war, but they had now to adjust to the following traumatic peace during which many of the industries supporting them had to look for new products and outlets.... There were gaps in library holdings due to wartime inaccessibility of key German periodicals, and a flood of new but haphazardly collected material to be absorbed from the British and American intelligence teams which followed hard on the heels of the conquering armies. Reports from the multitudes of militarily inspired projects had become exceedingly important but were not at all easy to trace and acquire, and every special library found it necessary to borrow so much material that interloans grew to become big business .... (pp. 22-23)

Under this avalanche, the resources of the SML and the British interlibrary loan system came under increasing strain.

The information crisis caused both the Royal Society and the British government to take action. A session of the Royal Society Empire Scientific Conference held in 1946 was dedicated to scientific information services, and at this session of the 1946 conference Bradford (1948) delivered a paper on his Law of Scattering. The 1946 conference recommended that the Royal Society hold another conference specifically dedicated to the handling of scientific literature, and the recommendation was implemented in 1948 with the convening of the Royal Society Scientific Information Conference. Two of the most active participants in the 1948 conference were Donald J. Urquhart and J. D. Bernal, who together played major roles-the first directly, the latter indirectly - in establishing the institutional bases of the bibliometric revolution.

\section{Urquhart's Law}

The Royal Society Scientific Information Conference marked the rise of Urquhart to prominence. He contributed no less than three papers to this conference. Trained as a physicist, Urquhart worked at the Science Museum Library and in 1948 transferred to the Department of Scientific and Industrial Research (DSIR), a governmental agency, which was established to promote scientific research during World War I, when it was realized that Britain did not have the capacity to produce such vital commodities as dyes, drugs, and optical glass. In 1956, Urquhart succeeded in obtaining the assignment of establishing the national scientific library, which Bradford had conceived and had begun to realize in the SML. Urquhart began this project with a study of the loans made by the Science Museum Library to outside organizations during 1956. This is the first large-scale study of library use, and Urquhart (1959) reported its results at the International Conference on Scientific Information, which was held in Washington, D.C., in 1958 and was inspired by the 1948 Royal Society information conference. Basically, he found two things. First, of the estimated 18,000 titles held by the Science Museum Library, 1250- or less than $10 \%$ of the titles-satisfied $80 \%$ of the 53,216 loans made by this library to outside organizations in 1956. Second, there was a positive relationship between the number of times periodical titles were borrowed from the SML and their holdings at major British libraries as shown by the British Union Catalogue of Periodicals (BUCOP). These findings caused him to formulate a law of supralibrary use (i.e., use of materials not in a given library but supplied either by interlibrary loan or through centralized document delivery). Urquhart (1977) once defined this law in the manner below:

In its more pedantic form the law states that the inter-library loan demand for a periodical is as a rule a measure of its total use. As far as I am aware the existence of such a law was first indicated in my report of a survey of the use of journals in the Science Museum Library in 1956. For this reason perhaps the law should be called Urquhart's Law. (p. 149).

Urquhart (1981) placed this principle at the basis of the operations of the National Lending Library for Science and Technology (NLLST), which he established in 1962 at Boston Spa, Yorkshire, writing:

The fact that the heaviest inter-library demand is for periodicals, which are held by a number of libraries is of major importance in designing inter-library services. To draw attention to this relationship I have called it "Urquhart's law." It means, for instance, that the periodicals in the Boston Spa collection which are rarely used are unlikely to be used to 
any appreciable extent in a British university. There may be some exceptions to this deduction.... Nevertheless, the law is very important in considering the need for a central loan collection. (p. 85).

Given its origins, the NLLST formed one of the institutional bases of the bibliometric revolution, and, through a number of reforms, it subsequently became the British Library Lending Division (BLLD) and later the present-day British Library Document Supply Centre (BLDSC).

\section{Garfield's Law}

The other active participant in the 1948 Royal Society Scientific Information Conference to be discussed, J. D. Bernal, is truly an interesting character. On the one hand, he was a leading scientist, playing an important role in the development of modern crystallography, and he was one of the founding fathers of molecular biology. Moreover, Bernal (1948a) was the first major scientist to validate independently Bradford's Law of Scattering, which he did in a paper delivered to the scientific information conference. On the other hand, Bernal was a committed communist, and, as such, he was particularly interested in the societal aspects of science, publishing in 1939 a major book entitled The Social Function of Science. It was this latter facet of Bernal that really defined his role at the 1948 conference, for Bernal (1948b) submitted to this conference a paper, whose essence was summed up by East (1998) in the following manner: "Implicit in his paper was the proposition that most journals in their existing form would be replaced by a national distribution scheme through which single papers would be distributed by central agencies" (p. 293). The proposal raised a storm in the British press over its implications of totalitarian planned science. Behind the furor was probably the knowledge that Bernal was an open supporter of Lysenko, who at that time was destroying Soviet genetics. The main opposition came from the British learned societies, the major publishers of scientific journals, who saw it as impinging upon their freedom and perogatives. Bernal was forced to withdraw his paper, and Sir Robert Robinson (1948), President of the Royal Society, alluded to this incident in his opening address with the following wry passage:

I notice that the writers of certain notices in the newspapers have allowed themselves to dwell, with evident relish, on the prospect of a clash of ideologies and the probable conflict between the planners and those who don't want to be planned. They are mistaken and will be disappointed. No delegate to this Conference has any aim other than the development of scientific information, but there may be differences of opinions about the methods. (p. 16)

However, although rejected in Britain, Bernal had an important influence on Eugene Garfield, who in 1951 began a career that ultimately led him to establish the other insti- tutional basis of the bibliometric revolution, the Institute for Scientific Information (ISI). It is one of the delightful anomalies of history that the rejected ideas of a British Communist played a major role in the establishment of a private American company. Garfield (1982) reports that one of his uncles gave him a copy of The Social Function of Science upon his graduation from high school and that he took it with him to the University of Colorado, where it was the subject of much discussion. This aspect of Bernal's influence on Garfield is interesting, for it helps explain the latter's close association with Robert K. Merton, a founder of the sociology of science, that was causal in information science assuming a more sociological approach in the U.S. than in Britain. Moreover, Garfield also reports that the proceedings of the Royal Society Scientific Information Conference "became a bible for me" (p. 511) and that Bernal's ideas of a centralized reprint center were in his thoughts during his development of the Science Citation Index (SCI.). In 1962, Garfield established personal contact with Bernal, who agreed to serve on the editorial advisory board of the SCI. So highly did Garfield (1976) think of Bernal that he placed the following dedication to him in the first published SCI Journal Citation Reports: "Dedicated to the memory of the late John Desmond Bernal whose insight into the societal origins and impact of science inspired an interest that became a career" (p. vii).

It was as a result of his research in developing the $S C I$ that Garfield (1972) formulated his bibliometric law. The pioneer investigation was undertaken by ISI in 1971, and it entailed the analysis of the approximately one million references that were published during the last quarter of 1969 in the 2200 journals then covered by the SCI. This 3-month sample was then matched against another random sample taken from the some 3.85 million references collected during all of 1969 to ensure that it was representative for the year as a whole. The results of this investigation led Garfield to the conclusion that a good multidisciplinary journal collection need contain no more than a few hundred out of an estimated 50,000-100,000 scientific and technical titles to provide effective coverage of the literature used most frequently by scientists. As evidence for this, he adduced that only 25 journals were cited in $24 \%$ of all references, that only 152 journals were cited in $50 \%$ of all references, that only 767 journals were cited in $75 \%$ of all references, and that only 2000 or so journals were cited in $85 \%$ of all references. Moreover, the data showed that only 540 journals were cited 1000 times or more a year and that only 968 journals were cited even 400 times a year. In this, the predominance of cores of journals was evident. The picture derived from the data caused Garfield (1972) to state his conclusion as follows:

... I can say that a combination of the literature of individual disciplines and specialties produces a multidisciplinary core for all of science comprising no more than 1000 
journals. The essential multidisciplinary core could, indeed, be made up of as few as 500 journals ... . (p. 476)

Garfield (1971) announced the formulation of a new bibliometric law in an article discussing the preliminary findings of this pioneer investigation, and he described its relationship to Bradford's Law of Scattering thus:

. . . At ISI, we are completing a study which has resulted in a generalization of Bradford's law[,] which, in a sense, "unifies" the demonstration of its validity in studies of individual fields. Allow me the eponymic shorthand of calling this unified theory or generalization "Garfield's law of concentration." The name is intended to suggest that, in opposition to scattering, a basic concentration of journals is the common core or nucleus of all fields. (p. 5)

Garfield (1979, pp. 21-23, 158-160) derived his Law of Concentration from Bradford's Law of Scattering by transposing the latter from that of a single discipline or subject to that of science as a whole. According to Garfield, there are as many different journal cores as there are special fields in science, but there is also a considerable amount of overlap. He compared Bradford's Law to a comet with the journal nucleus representing the head and the succeeding journal zones as the tail that becomes wider in proportion to the distance from the head. Employing this analogy, Garfield defined his Law of Concentration as stating that "the tail of the literature of one discipline consists, in large part, of the cores of the literature of other disciplines" (p. 23). According to him, this concentration effect is so great that it is possible to provide adequate coverage of all science with only a relatively small number of journals.

In the article announcing his law, Garfield (1971) portrayed its significance for libraries with a story about a meeting of a group of librarians representing unrelated fields like plasma physics, pharmacology, ecology, metallurgy, etc. All the librarians are carrying lists of 500-1000 journals, which they intend to order to satisfy the journal needs of their respective special libraries. In this depiction, the meeting is shaken up by a seismic event that mixes up the librarians and their lists, causing each librarian to establish a journal collection meant for another special library. The moral of Garfield's story is that the consequences of the seismic event are negligible, that "each librarian finds that "his' list has produced a collection admirably suited to the needs of his special library," and that "[t]he law of concentration would have predicted just that result in the scene imagined" (p. 6). It is interesting to note that Garfield (1959) was present and made comments at the session of the 1958 International Conference on Scientific Information in Washington, D.C., where Urquhart presented the paper that laid the bases for his law on supralibrary use.

\section{The Controversy}

Urquhart's and Garfield's laws are historically significant, because they formulate the principles underlying the operations of the two organizations, which comprised the institutional bases of the bibliometric revolution. We now come to the important question of what the relationship is between these two laws-Urhquhart's stating that supralibrary use concentrates on a relatively few journals that are most widely held by libraries, and Garfield's positing that the bulk of citations concentrate on a small, multidisciplinary core of journals. If there is a strong correspondence between supralibrary use and citations, then significant science and technology is restricted to a relatively few important journals. However, if there is no or little correspondence between supralibary use and citations, then the scientific information system is less structured and more open than these two laws seem to indicate.

This question was analyzed at the British Library Lending Division (BLLD) shortly after its formation by the amalgamation of the NLLST with the National Central Library in 1973, and after Maurice B. Line had succeeded Urquhart as Director General in 1974. The analysis was done by Pauline A. Scales (1976) with the same 1969 citation data, which Garfield had utilized in his pioneer investigations and then published. Scales compared this data to a NLLST use survey conducted in 1969 of journal issues for the years 1967, 1968, and 1969. To make the use and citation data comparable, she excluded any NLLST titles that did not also appear among the $S C I$ source journals and considered citations to only the 1967-1969 issues. Her final lists consisted of 1571 journals ranked in descending order by frequency of NLLST use and 880 journals ranked in descending order by frequency of SCI citations. She validated her use data by testing the hypothesis that NLLST use was typical of that in Britain generally through Urquhart's method of comparing the frequency of this use to the number of holdings in British libraries as shown in $B U C O P$. Scales obtained the same result (i.e., "there is a definite tendency for those journals used less frequently to be those held by the least number of libraries and vice versa, suggesting that the hypothesis is a reasonable one") (p. 21).

Scales used the Spearman rank correlation as her basic method of comparing NLLST use to SCI citations. This is a nonparametric statistical technique utilized to counteract the problems of the highly skewed distributions underlying library and information science data by converting interval ranks, the distances between which increase exponentially as one goes up the ranks, to equidistant ordinal ranks. She calculated Spearman rank correlation coefficients both of the 50 titles highest in NLLST use with their corresponding citation ranks and of the 50 titles highest in SCI citations with their corresponding use ranks. In both cases, she modified the corresponding citation and use ranks to the same ranking scale of 1-50 as the initial variable, with which they were being correlated. For the 50 titles highest in NLLST use, Scales obtained a significant correlation of 0.42 , and for the 50 titles highest in SCI citations, she calculated an insignificant correlation of 0.26 . Scales then compared the number of journal titles common to the top 10, 20, 30, etc., 
of the two lists. For the top 50 she found only 16 titles in common, and she had to consider more than 250 titles before even 50\% occurred on both lists. Moreover, Scales found that the correlation of citations with use decreased as one went down the ranks, calculating a Spearman rank correlation of merely 0.002 between the titles ranked from 51 to 100 in citations and their corresponding NLLST use ranks. As a result of this analysis, Scales came to the conclusion that "ranked lists produced by analyses of citations do not constitute valid guides for journal selection by libraries" (p. 17). The two institutional bases of the bibliometric revolution were now in conflict with each other.

The publication of the Scales article marked the start of a major controversy, during which both Urquhart's and Garfield's laws were called into question. In respect to the former, Rowley (1976) of the Department of Librarianship, City of Birmingham Polytechnic, delivered the most cogent assault, the essential part of which is quoted below:

This leads us to my major criticism in Pauline Scales' work. She relies on use data from a survey carried out by the NLL in 1969, to give a measure of the frequency of use of journals published in 1967, 1968, and 1969 in the NLL's stock. Every practising librarian knows that the requests forwarded to the NLL are unique in some way e.g. fringe, obscure, or foreign items. The core demand on most libraries is met from their own stock without recourse to the NLL. Demands on the NLL's services may reflect certain individual user's core demands, but this can only be a small group. Journals which are core journals in a subject field, in the sense that many libraries purchase them, and many readers consult them, are not normally those which will be obtained from the NLL ... . I cannot accept the thesis that the demand on NLL stock is in any way typical of the demand in any other type of library, or of demand and use of periodicals generally. (p. 319)

Rowley dismissed Scale's attempt to validate NLLST use by comparing it to the number of holdings listed in $B U C O P$ by stating that " $B U C O P$ can hardly be taken as a representative list of UK library holdings" and that "a low number of locations does not necessarily imply low usage" (p. 319). The same line of attack was taken by Cawkell (1977, 1978), ISI's representative in Britain, who described Scales' NLLST use list as "fortuitous" (1977, p. 151) and declared that "a fringe corpus, derived in this way, is not acceptable as a definitive list" (1978, p. 45). These same opinions were expressed in Pan (1978) and Bensman (1982).

The criticism of the Scales' study drew ripostes from both Urquhart and Line. For his part, Urquhart (1977) restricted himself to a defense of his law and concentrated his fire on Rowley, stating, "It is a serious matter when a lecturer in a library school contradicts without producing any evidence one of the most useful laws in library science" (p. 149). He noted that his law had been corroborated by further studies at Boston Spa, the University of Newcastle, and in the USA. Urquhart summed up the logic underlying his law thus:

I appreciate that if you think all organizations have their core journals and have to rely on borrowing peripheral journals Urquhart's law seems to be unreasonable. However, this line of reasoning leads to the conclusion, that the most heavily used journals at Boston Spa would be the very uncommon journals of which Boston Spa has possibly the only holding. This is clearly not the case so the line of reasoning is wrong. The trouble is that it focuses attention on what an organization does about periodicals and not on what happens to particular periodicals. If you think in terms of individual periodicals you would have a "core" of users: that is those organizations holding a periodical and some peripheral users, that is those who have to borrow it. It is reasonable to suggest the larger the core the larger the periphery. Indeed this line of reasoning leads to the conclusion that the law would also apply to monographs. (p. 149)

Urquhart then took aim at the interlibrary loan situation in the United States:

... A deduction from this law is that the heaviest interlibrary loan demand is for the commonest items and these are the ones that the holding libraries have no wish to lend as they are heavily used locally. A failure to appreciate this ... has hindered the development of satisfactory interlibrary lending services in a number of countries including the USA and India. (p. 149)

He concluded, "If a library system is not to make mistakes about inter-library policies in the future it is important that Urquhart's law should be taught to all library school students" (p. 149). The experience could not have been a pleasant one for Rowley, given that Urquhart was now an eminent figure, as recognized by the British government in his award of a CBE.

Although Urquhart limited himself to his answer to Rowley, Line was quite prolific in his responses to the criticisms of the Scales study. However, as a result of the Scales study, he came to question the universal validity of not only Garfield's but also Urquhart's Law. Line (1977) presented his most reasoned argumentation in a paper provocatively entitled "On the Irrelevance of Citation Analyses to Practical Librarianship." Here Line identified himself with the Scales study by prefacing his summary of its results with the statement, "More recently, I and a member of my staff carried out some comparisons" (p. 51) on the question of the validity of citations as indicators of library use. In dealing with the criticisms of Urquhart's Law, Line focused on the special nature of NLLST use. One of the main reasons the NLLST had been founded was to support British industry, and a survey conducted in December, 1968, shortly before the use study employed by Scales, revealed that the library was fulfilling this function (National Libraries Committee, 1969, pp. 29, 256-265). According to this survey, the 
greatest number of publications (about $40 \%$ of the sample) was sent to industrial users, and the next largest group of users was the universities with about $25 \%$ of the satisfied requests. No other category of users exceeded $10 \%$ of the survey sample. Line (1977) utilized this fact to explain the type of journal most heavily borrowed from the NLLST:

An obvious retort is that interlibrary loan requests presumably represent marginal uses, and so are untypical of uses in an ordinary library. In fact, however, the journals most requested from BLLD are those most commonly held by libraries, and many of them have large circulations. They include such journals as Science, New England Journal of Medicine, and Nature. The reason is that most of the libraries using the BLLD, especially for scientific journals, are not general research libraries but special industrial libraries. Journals which are central to a university library are marginal for many special libraries, which may not take, or may quickly discard, journals such as Nature. It seems quite likely that interlibrary loan requests to BLLD are quite a good indication of uses in a general academic library. ( $p$. 52)

In seeking reasons for the apparent low rank correlation of NLLST use with SCI citations, Line listed the following possibilities: (1) some users, especially in industrial research, read but publish little, so that their uses would be little reflected in citations; (2) the $S C I$ citation analyses were derived entirely from journal sources, and the lack of monograph coverage may have introduced serious distortions; and (3) a high proportion of the SCI source journals were American and may have reflected American rather than British use, of which NLLST use was a reflection. All this caused Line to wonder not only whether citation studies were valid indicators of library use but even whether they were reliable indicators of citations. To test this hypothesis, he conducted a simple experiment by performing rank-order correlations among lists of journals ranked by number of citations derived from different cores of source journals, finding widely ranging overlaps $(35-80 \%)$ and correlation coefficients $(0.28-0.86)$ among the various lists. In Line's opinion, the main reason for these wide variations was probably similar to why use data differed from library to library: as every library is unique, so every source journal, or group of source journals, is unique, and every source year is unique. Due to these reasons, Line rejected the validity of any generalized use study - citation or library — stating that "any librarian would be better advised to study the uses and interlibrary loan requests of his own users" (p. 52).

\section{A Resolution of the Controversy}

A close examination of the Scales study reveals its utilization of statistics to be seriously flawed in both concept and execution. As a result of this, the paper was subjected to severe criticism by B. C. Brookes (1976), whose ideas on statistical matters are of extreme interest, for he taught library science at University College London (UCL), the epicenter of the biometric revolution, where the bases for modern inferential statistics were laid. His approach toward Bradford's Law of Scattering soon came to reflect the influence of the work done at the UCL Department of Statistics, the first university statistics department in the world, and housed in a building named after Karl Pearson.

Brookes began his criticism of the Scales' study by stating that its conclusion (i.e., that citations are not reliable indicators of library use) did not follow from its methods. He found two major flaws with these methods. The first related to the utilization of the Spearman rank-correlation and the resultant ignoring of the frequency data, on which the ranks were based. Brookes noted that Spearman had been an experimental psychologist, who had devised his correlation coefficient to compare ranks derived from subjective judgments rather than frequencies, and he described as "dubious" the Spearman equating of the ordinal 1st with the cardinal number 1, the ordinal 2nd with the cardinal number 2, and so on. According to him, the Spearman correlation is based on implicit assumptions about the underlying probability distribution of the entities being ranked, which Scales did not seem to have adequately explored. Noting that the Scales' lists were ranked in descending order of frequency and that the citation rank in the list of the top 50 titles by NLLST use was cut off at rank $=881$, Brookes argued that as a result of these assumptions the technique applied gave equal weight to a shift from rank $=880$ to rank $=881$ as to a shift from rank $=1$ to rank $=2$. He then stated, "Judging by what I have seen of similar lists published by ISI, a technique which correlates ranks on that basis is wholly unrealistic" (p. 321). The other major flaw, which Brookes found with the Scales paper, related to the stability of the ranks at the lower end of the distributions. Using again the example of the citation ranks of the journals in the NLLST use list, Brookes pointed out that at rank $=881$, the frequencies were down to 4 , so that presumably rank $=882$ corresponded to a frequency of 3 . He then proved that in the context under discussion, frequencies of 3 and 4 are much too low to be considered as a basis for calculations based on ranks. The main thrust of his argument here was that the lists published by ISI should be considered as samples of the current scene and that sample variability alone could account for major changes in rankings at the lower end of the distributions. As a result of his analysis, Brookes concluded: "The hypothesis that citation counts of serials are of little use as indicators of usage therefore remains unproven by the techniques described in her paper" (p. 321).

The publication of the Scales paper marked the start of an important transition in Brookes, during which he started to connect the bibliometric with the biometric revolution. Brookes (1977a) spelled out the problem by stating that computerized information systems such as that producing the $S C I$ had begun to pour out a superabundance of data before the development of the mathematical/statistical tech- 
niques required to make proper use them. The faulty use of the Spearman correlation coefficient in the Scales study caused Brookes and Griffiths (1978) to experiment with frequency-rank distributions in an attempt to create such a technique. During this process, Brookes (1977b, 1980) explored Bradford's law as an extremely mixed Poisson process, connecting it with the negative binomial distribution, which biologists use to model concentration patterns in nature. Thus, both institutionally and intellectually, Brookes served as a link between the bibliometric and biometric revolutions.

In the heat of the controversy engendered by the Scales study, Line continued to evolve his ideas on the utility of ranked lists of journals for libraries in the management of their serials collections. Of the Scales study itself, Line (personal communication, January 28, 2000) has recently written in the light of a continuing correspondence between us:

[The Scales article] was partly based on the false premise that NLLST data might be useful, and wrongly concluded that SCI data did not correlate well so they weren't useful. They aren't useful, but not for that reason.

However, documents of the period do show that Line initially toyed with this premise. Thus, in the first exchange of letters over the Scales study published by the Journal of Documentation in its December 1976 issue, Line and Scales (1976) made in their reply to the critics the following two points manifesting support of Urquhart's Law and rejection of Garfield's Law:

\begin{abstract}
2. Subsequent work at BLLD has shown that there is a very good correlation between rank lists of journals used at three university libraries and the BLLD rank list, and BLLD rankings have proved useful in identifying low use titles at the Newcastle upon Tyne University Library ....

4. Since citation rank lists based on different source journals show striking differences, the statistical probability that any one of them, based on however large a number of source journals, will fit any one library must be very small. (p. 322)
\end{abstract}

However, by the next exchange of letters published by the Journal of Documentation in its June 1977 issue, Line had concluded that the above premise of the Scales study was not correct. In this exchange, Line and Steemson (1977) reported the need to make modifications both to the initial Scales article and to the letter of reply as a result of further research and analysis done at the BLLD. Although acknowledging the weakness of the Spearman rank correlation technique, they utilized it as their main analytical tool to prove that ranked lists of journals are of no use to librarians in serials collection management, because nowhere along the distributions are the correlations high enough for librarians to make precise determinations as to what belongs or does not belong in their collections. Applying this logic to the
SCI citation list, Line and Steemson wrote of the Scales article:

... What librarians need to know is not the core journals in a field, which are well enough known anyway, but what journals outside this core they should acquire. The method used in the [Scales] article, of calculating a separate rank correlation coefficient for the second 50 most cited (i.e. ranked 51-100) titles, is not valid. This gave values of 0.26 and 0.002 respectively; if the 100 most cited titles are taken together a coefficient of 0.28 is obtained. While this is not a very strong positive correlation it is none the less significant at the $1 \%$ level. However, the fact that the first 100 correlate significantly still does not help the librarian; if he is to select marginal journals with any accuracy, he needs a very high correlation indeed, much higher than 0.28 . In fact, it is possible to achieve quite high correlation coefficients with substantial differences in the order of particular items. The coefficient for the 880 titles common to both the use and the citation lists is approximately 0.6 , but this conceals innumerable substantial variations ... (p. 152)

Having thus dealt with Garfield's Law, Line and Steemson turned to Urquhart's Law:

... it was stated in the letter in the December issue that good correlations had been found between the BLLD rank list and rank lists of several academic libraries. The Spearman rank correlation coefficients are indeed statistically significant, but further study has shown that the full story is more complex. Two of the lists were rather too short ... for any conclusions to be drawn. The third, of 565 titles, gave a rank correlation coefficient of 0.42 when ranked by BLLD use. This is very significant, but not sufficiently high for the BLLD list to be of real value to the library in question as a selection tool. Only 15 titles were ranked above 50 in both lists and 34 above 100 in both. When the rank correlation coefficients were calculated for the 50 most used titles in the BLLD and the university lists, values of 0.23 and 0.45 respectively were obtained. These results are remarkably similar to the values of 0.42 and 0.26 for the top 50 of the BLLD and ISI lists. (p. 152)

Line and Steemson then declared that the main conclusion of the Scales article-that citation rank lists are poor indicators of library use and of little practical interest or value to librarians - still held true but then stated that the BLLD rank list suffered from similar disadvantages. Line had rejected the universal validity of Urquhart's Law and placed it in the same category as Garfield's Law.

Line's main contention during the controversy is entirely valid. Rank order depends on numerous factors, and librarians must take all these factors into account in managing their collections. Among most important of these factors is the structure of the set, within which a given rank order arises. Library and information science sets are fuzzy and can be composed of many different components. Depending on the selection of components, a given component may 
occupy a different rank within the set. However, the way in which Line made this point obscured the fundamental correspondence between Urquhart's and Garfield's laws. In essence, Line required the precision of a mathematical function for the applicability of rank lists of journals, when in fact he was dealing with a statistical relationship. To use a military analogy, he required journals to form ranks like soldiers in the Coldstream Guards, whereas statistics deal with the relationships between sets of motley rabble varying about their respective means. His employment of the Spearman rank-correlation technique ignored the effects of the highly skewed distributions in library and information science combined with the mixed Poisson process that leads to these distributions. Under such a process, journals are used or cited over time at differing mean rates that vary within certain confidence limits. Given highly skewed distributions, where the interval distances between the mean rates of the vast proportion of the journals are either exceedingly small or even nonexistent, Brookes' point about sample variability in respect to these journals is entirely valid, as small changes in interval distances from sample to sample can lead to large changes in their rank order. Under such conditions, Spearman rank-correlation coefficients of 0.6 and 0.42 for given samples should be considered extraordinarily high.

To demonstrate this point, I will now present how I reworked the Scales data for the top 50 journals in both NLLST use and SCI citations in a way that partly met Brookes' two main criticisms of the Spearman rank-correlation technique in respect to its ignorance of frequency data and the stability of the ranks at the lower ranges of the distribution. In doing this, I used the chi-square test of independence. It is not without historical interest to note that this test was pioneered by Karl Pearson, the principal figure of the biometric revolution, who, like Brookes, taught at University College London, although in an earlier period.

In her paper, Scales (1976) stated that her list for frequency of NLLST use contained 1571 journals and that her list for frequency of SCI citation had 880 titles. She ranked both lists in descending order of use and citation, ordinally ranking them $1,2,3,4$, etc. At the end of the paper, she placed an appendix that contained two rankings. The first was of list of the top 50 titles by NLLST use in descending order with their corresponding absolute SCI citation ranks, which ranged from 2 to several titles at 881 . Because there were 1000 titles on the SCI citation list serving as her source, it seems that she assigned the rank 881 to all those titles that fell below rank 880 on the SCI list. For my purposes, I lumped all these at rank 880 . The other ranking in the appendix listed the top 50 titles by frequency of SCI citation with their corresponding absolute NLLST use ranking, which ranged from 1 to 708. There were 16 titles in common to both rankings, which thus contained a total of 84 titles upon combination.

My first step in the analysis of the Scales data was to classify the 50 journals in both the NLLST and the SCI rankings according to the subject categories in the 19651969 cumulation of the SCI. The 50 NLLST journals classified in 59 subject categories, whereas the 50 SCI titles were assigned to 65 subject categories. In each case, there were more subject categories than journals, and this can be attributed to the tendency of library and information science sets toward fuzziness, as ISI had found it necessary to classify certain titles in two or more subject categories. For example, one narrowly focused journal, Virology, was classified by ISI in four subject sets-Immunology, Medicine, Microbiology, and Virology — and one can be certain that its relative citation rank differed within these sets so disparate in size and orientation. Inspection of the NLLST and SCI subject categories corroborated Line's admonitions about the uniqueness of different rank lists, because NLLST use and $S C I$ citations seemed to operate on dissimilar principles. NLLST use appeared to be oriented toward technology, whereas the SCI citations were more reflective of basic science. The clearest evidence for this was that 13 NLLST titles classified in engineering categories due to the high proportion of use attributable to industrial libraries, but no $S C I$ journals appeared in these categories.

My next step in the analysis of the Scales data was to base the NLLST use and SCI citation variables on a concept, which I derived from Bradford zones. To do this, I defined three zones ordinally ranked high, medium, and low, whose basic purpose was to provide a rough model of a Bradfordtype distribution. The high zone was designed to encompass the top $10 \%$ of the 1571 NLLST use titles as well as the top $10 \%$ of the 880 SCI citation titles. Experience with library and information science distributions had indicated to me that this upper stratum could be estimated to account for approximately $50 \%$ of the total frequencies of such a distribution. For example, Urquhart had found that the top $10 \%$ of the titles had accounted for 80\% of SML uses in 1956. With this in mind, I had the High NLLST Use zone encompass ranks 1-157 and the High SCI Citations zone range from rank 1 to rank 88. Considering the upper quartile a good statistical concept, I designed the medium zone to encompass the next $15 \%$ of the titles. Again, experience with library and information science distributions had indicated to me that this zone should account for $25 \%$ of the total frequencies of such a distribution. Together, the upper and medium zones comprising the upper $25 \%$ of the titles could be considered to account for $75 \%$ of the total frequencies - an estimate in line with Trueswell's 80/20 Rule. Accordingly, I assigned the Medium NLLST Use zone use ranks 158-390, which gave it 233 or $14.8 \%$ of the use titles; and I allocated the Medium SCI Citations zone citation ranks $89-218$, which caused it to have 130 or again $14.8 \%$ of the citation titles. The remaining ranks were assigned to the low zone, which thus was designed to contain the bottom $75 \%$ of the titles. Experience had shown that this zone should account for only $25 \%$ of the frequencies. To create the Low NLLST Use zone, I assigned it use ranks $391-1571$, giving it 1181 or roughly $75.2 \%$ of the use titles; 
TABLE 1. $3 \times 3$ Contingency table for the chi-square test of independence of NLLST use from SCI citations.*

\begin{tabular}{|c|c|c|c|c|}
\hline & & High $S C I$ citations & Medium $S C I$ citations & Low $S C I$ citations \\
\hline & & $\begin{array}{l}\text { Ranks } 1-88 \text { No. high } \\
\text { citation titles }=88 \% \text { high } \\
\text { citation titles }=10.0 \%\end{array}$ & $\begin{array}{l}\text { Ranks } 89-218 \text { No. medium } \\
\text { citation titles }=130 \% \text { medium } \\
\text { citation titles }=14.8 \%\end{array}$ & $\begin{array}{l}\text { Ranks } 219-880 \text { No. low } \\
\text { citation titles }=662 \% \text { low } \\
\text { citation titles }=75.2 \%\end{array}$ \\
\hline High NLLST use & NO & 38 & 11 & 18 \\
\hline Ranks $1-157$ & $\% \mathrm{O}$ & $45.2 \%$ & $13.1 \%$ & $21.4 \%$ \\
\hline No. high use titles $=157$ & $\mathrm{NE}$ & 0.8 & 1.2 & 6.3 \\
\hline Percent high use titles $=10.0 \%$ & $\% \mathrm{E}$ & $1.0 \%$ & $1.5 \%$ & $7.5 \%$ \\
\hline Medium NLLST use & NO & 13 & 0 & 0 \\
\hline Ranks $158-390$ & $\% \mathrm{O}$ & $15.5 \%$ & $0.0 \%$ & $0.0 \%$ \\
\hline No. medium use titles $=233$ & $\mathrm{NE}$ & 1.2 & 1.8 & 9.4 \\
\hline Percent medium use titles $=14.8 \%$ & $\% \mathrm{E}$ & $1.5 \%$ & $2.2 \%$ & $11.2 \%$ \\
\hline Low NLLST use & NO & 4 & 0 & 0 \\
\hline Ranks 391-1571 & $\% \mathrm{O}$ & $4.8 \%$ & $0.0 \%$ & $0.0 \%$ \\
\hline No. low use titles $=1181$ & $\mathrm{NE}$ & 6.3 & 9.3 & 47.5 \\
\hline Percent low use titles $=75.2 \%$ & $\% \mathrm{E}$ & $7.5 \%$ & $11.1 \%$ & $56.6 \%$ \\
\hline
\end{tabular}

* 84 journals in Scales listing of top 50 titles in both NLLST use and SCI citations. NO = number observed, $\% \mathrm{O}=$ percent observed, $\mathrm{NE}=$ number expected, $\% \mathrm{E}=$ percent expected.

Cell numbers expected and cell percents expected were calculated in the following way. First the cell, percents expected, were obtained by multiplying the $\%$ use and the $\%$ citation titles at each corresponding use/citation level. The cell, percents expected, were then multiplied by 84 to calculate the corresponding cell numbers expected. Of the 18 high NLLST use/low SCI citation titles, 12 were engineering journals.

to make the Low SCI Citations zone, I allocated it citation ranks $219-880$, giving it 662 or again roughly $75.2 \%$ of the citation titles. With this done, I assigned ordinal use and citation ranks to the 84 journals listed in the appendix of the Scales article by locating their position in the above zones on the basis of the absolute NLLST use and SCI citation ranks given them in this appendix. By this method, I hoped to counter Brookes' two main criticisms of the Spearman rank-correlation technique. First, I introduced some concept of the distribution of the frequencies, on which the ranks are based. Second, I stabilized the ranks due to the following reason: Although the journals can easily change ranks from sample to sample particularly at the lower end of the distributions, it is much more difficult for them to change zones, given the interval distances. Moreover, the approach of working with journals within broad zones seems much more realistic in terms of practical collection management, where due to the complexity of the variables, the best librarians can hope for is not mathematical precision but to be-pardon the Americanism-somewhere in the ball park. Therefore, a librarian may be better served by relying not on such precise statistical techniques as correlation but on rougher ones such as the chi-square test of independence that are more robust in the face of these variables and can clearly predict with reasonable accuracy at least in what broad use zone his or her journal selections will fall.

To perform the chi-square test of independence, these ordinal use and citation zones were cast into a $3 \times 3$ contingency table shown above as Table 1 . The purpose of this table is to set up the null hypothesis that there is no relationship between NLLST use and SCI citations. This is done by comparing the distribution of observations over the cells expected under the null hypothesis with the distribu- tion of the observations that was actually observed. Under the null hypothesis, the distribution of the 84 Scales titles should be in proportion to total number of titles in each cell. The standard method of calculating expected frequencies in a contingency table is to multiply the frequencies of the two variables interlocking on a cell and then dividing the resulting product by the total number of frequencies in the data set being tested. In a variation on this method, I first multiplied the percent of the titles encompassed by the use and citation zones interlocking on a given cell and then multiplied the resulting product by 84 to obtain the number of Scales titles expected in the cell under the null hypothesis. For example, since the High NLLST Use zone and the High SCI Citations zone encompassed respectively $10 \%$ of the total use and total citation titles, the Percent Expected of Scales titles in the High NLLST Use/High SCI Citations cell was $1.0 \%$ and the Number Expected of such titles was roughly 0.8 . In contrast, the actual Number Observed of Scales titles in this cell was 38. Looking at the other end of the distribution, both the Low NLLST Use zone and the Low SCI Citations zones were designed to contain about $75.2 \%$ of their respective titles. Therefore, multiplication of these percents made the Percent Expected of the Scales titles in the Low NLLST Use/Low SCI Citations cell come out to be roughly $56.6 \%$ and the Number Expected to be 47.5. However, the Number Observed was actually zero. In general, inspection of the cells in Table 1 reveals a strong positive relationship between NLLST use and SCI citations. Only in the High NLLST Use/Low SCI Citations cell does the relationship seem to be strongly negative with the Number Expected at 6.3 and the Number Observed at 18. However, of the 18 titles observed in this cell, 12 were engineering journals, reflecting the high proportion of industrial 
TABLE 2. Chi-square test of independence of NLLST use from $S C I$ citations.*

\begin{tabular}{lccr}
\hline \multicolumn{1}{c}{ Cell $^{a}$} & $\begin{array}{c}\text { Observed } \\
\text { frequency }\end{array}$ & $\begin{array}{c}\text { Expected } \\
\text { frequency }\end{array}$ & Chi-square \\
\hline $\begin{array}{l}\text { High NLLST use/high } S C I \\
\quad \text { citations }\end{array}$ & 51 & 2.1 & $1,147.4$ \\
$\begin{array}{l}\text { High NLLST use/medium } \\
\quad \text { SCI citations }\end{array}$ & 11 & 3.1 & 20.4 \\
$\begin{array}{l}\text { High NLLST use/low } S C I \\
\quad \text { citations }\end{array}$ & 18 & 15.7 & 0.3 \\
$\begin{array}{l}\text { Low NLLST use/high } S C I \\
\quad \text { citations }\end{array}$ & 4 & 6.3 & 0.8 \\
$\begin{array}{l}\text { Low NLLST use/medium } \\
\quad \text { SCI citations }\end{array}$ & 0 & 9.3 & 9.3 \\
$\begin{array}{l}\text { Low NLLST use/low SCI } \\
\quad \text { itations }\end{array}$ & 0 & 47.5 & 47.5 \\
$\quad$ Total chi-square $=$ & & & 1335.8 \\
\hline
\end{tabular}

$*$ Degrees of freedom $=5$.

Independence of NLLST use from SCI citations rejected at the 0.005 level at any chi-square above 16.75 .

${ }^{a}$ To meet the test's requirements that no expected frequency should be below one and two expected frequencies may be near one provided that most of the other expected frequencies exceed five, the High NLLST Use cells were combined with their respective Medium NLLST Use cells to form new High NLLST Use cells.

libraries among the NLLST users and corroborating Line's observations about the uniqueness of different rank lists.

The results of the actual chi-square test of independence are shown above in Table 2. This test was developed by Karl Pearson, and its aim is to determine how well the observed frequencies of an actual distribution fit the expected frequencies calculated from a theoretical distribution. Interpretation of this test is fairly simple: the closer the fit, the lower the chi-square; the worse the fit, the higher the chi-square. Snedecor and Cochran (1989, pp. 77-78) stipulate as a working rule for the chi-square test that no expected frequency should be below one, and that two expected frequencies may be near one provided that most of the other expected frequencies exceed five. According to them, if this condition is not met, the cells must be combined in such a way that it is met. To achieve this effect, I combined the High NLLST Use cells with their respective Medium NLLST Use cells to form new High NLLST Use cells. As can be seen in Table 2, the total chi-square was calculated to be 1225.8 with the vast bulk of the chisquare-1147.4 - deriving the High NLLST Use/High SCI Citations cell. With five degrees of freedom, rejection of the null hypothesis of the independence of NLLST use from SCI citations occurs at any chi-square larger than 16.75 . When presented with this analysis, Line (personal communication, January 28, 2000) wrote:

I am now convinced that NLLST data correspond well with $S C I$ data, and I have always said that BLDSC/NLLST use corresponds closely with aggregate library use. The only point of difference between us is that I don't think either
BLDSC or SCI data should be used for local collection management.

Thus, in my opinion, the controversy is for the most part resolved. Urquhart's and Garfield's Laws mutually corroborate each other, and the scientific and technical information system is highly structured and restrictive. In the words of the title of the British novel by John Braine, there is very little room at the top. Moreover, the points made by Line are also largely valid. As soon as librarians attempt to adapt their local collections to the nature of the scientific and technical information system emerging from these laws, they immediately confront the issues advanced by Line, and among the most important of these issues is how to structure their sets in such a way so as to obtain the journal rank orders that best meet the needs of their user populations.

\section{References}

Ashworth, W. (1975). Special libraries in the UK in recent years. In K. Barr \& M. Line (Eds.), Essays on information and libraries: Festschrift for Donald Urquhart (pp. 17-27). London: Clive Bingley.

Bensman, S.J. (1982). Bibliometric laws and library usage as social phenomena. Library Research, 4, 279-312.

Bensman, S.J. (2000). Probability distributions in library and information science: A historical and practitioner viewpoint. Journal of the American Society for Information Science, 51, 816-833.

Bernal, J.D. (1948a). Preliminary analysis of pilot questionnaire on the use of scientific literature. In The Royal Society Scientific Information Conference, 21 June-2 July 1948: Report and Papers Submitted (pp. 589-637). London: The Royal Society.

Bernal, J.D. (1948b). Provisional scheme for central distribution of scientific publications. In The Royal Society Scientific Information Conference, 21 June-2 July 1948: Report and Papers Submitted (pp. 253-258). London: The Royal Society.

Bradford, S.C. (1934). Sources of information on specific subjects. Engineering, 137, 85-86.

Bradford, S.C. (1948). Complete documentation. In The Royal Society Empire Scientific Conference, June-July 1946: Report (Vol. 1, pp. 729-748). London: The Royal Society.

Brookes, B.C. (1976). Citation v. usage of serials. Journal of Documentation, 32, 320-332.

Brookes, B.C. (1977a). Frequency-rank distributions. Journal of Documentation, 33, 153-154.

Brookes, B.C. (1977b). Theory of the Bradford Law. Journal of Documentation, 33, 180-209.

Brookes, B.C. (1980). The foundations of information science, Part II, Quantitative aspects: Classes of things and the challenge of human individuality. Journal of Information Science, 2, 209-221.

Brookes, B.C., \& Griffiths, J.M. (1978). Frequency-rank distributions. Journal of the American Society for Information Science, 29, 5-13.

Cawkell, A.E. (1977). Citations, review serials, and journal rankings. Journal of Documentation, 33, 150-151.

Cawkell, A.E. (1978). Evaluating scientific journals with Journal Citation Reports - a case study in acoustics. Journal of the American Society for Information Science, 29, 41-46.

East, H. (1998). Professor Bernal's "insidious and cavalier proposals": The Royal Society Scientific Information Conference, 1948. Journal of Documentation, 54, 293-302.

Garfield, E. (1959). [Comments]. In Proceedings of the International Conference on Scientific Information, Washington, D.C., November 16-21, 
1958 (Vol 1, pp. 311-312). Washington, D.C.: National Academy of Sciences, National Research Council.

Garfield, E. (1971). The mystery of the transposed journal lists-wherein Bradford's Law of Scattering is generalized according to Garfield's Law of Concentration. Current Contents, 3, 5-6.

Garfield, E. (1972). Citation analysis as a tool in journal evaluation. Science, 178, 471-479.

Garfield, E. (Ed.) (1976). Science Citation Index: 1975 Annual: Vol 9. Journal Citation Reports. Philadelphia: Institute for Scientific Information.

Garfield, E. (1979). Citation indexing - its theory and application in science, technology, and humanities. Philadelphia: ISI Press.

Garfield, E. (1982). J.D. Bernal, the sage of Cambridge, 4S award memorializes his contribution to the social studies of science. Current Contents, $19,5-17$.

Line, M.B. (1977). On the irrelevance of citation analysis to practical librarianship. In EURIM II: A European conference on the application of research in information services and libraries (p. 51-56). London: Aslib.

Line, M.B., \& Scales, P.A. (1976). Mr Line and Ms Scales write. Journal of Documentation, 32, 322.

Line, M.B., \& Steemson, R.J. (1977). Comparisons of ranked lists of journals. Journal of Documentation, 33, 151-153.
Lotka, A.J. (1926). The frequency distribution of scientific productivity. Journal of the Washington Academy of Sciences, 16, 317-323.

National Libraries Committee (1969). Report of the National Libraries Committee: Presented to Parliament by the Secretary of State for Education and Science by command of Her Majesty, June 1969 (Cmnd. 4028). London: Her Majesty's Stationary Office.

Robinson, R. (1948). [Opening address]. In The Royal Society Scientific Information Conference, 21 June-2 July 1948: Report and Papers Submitted (pp. 15-17). London: The Royal Society.

Rowley, J.E. (1976). Citation analysis. Journal of Documentation, 32, 318-320.

Scales, P.A. (1976). Citation analyses as indicators of the use of serials: A comparison of ranked lists produced by citation counting and from use data. Journal of Documentation, 32, 17-25.

Snedecor, G.W., \& Cochran, W.G. (1989). Statistical methods (8th ed.). Ames: Iowa State University Press.

Urquhart, D.J. (1959). The use of scientific periodicals. In Proceedings of the International Conference on Scientific Information, Washington, D.C., November 16-21, 1958 (Vol 1, pp. 287-300). Washington, D.C.: National Academy of Sciences, National Research Council.

Urquhart, D.J. (1977). Urquhart's Law. Journal of Documentation, 33, 149. 